\title{
The correlation between serum insulin-like growth factor 1 level and body weight in children with a height less than the $10^{\text {th }}$ percentile
}

\author{
Xianglan Wen, Qiong Tang, Yican Yang
}

Zhuzhou Central Hospital, China

Submitted: 11 December 2019; Accepted: 8 October 2020

Online publication: 9 May 2021

Arch Med Sci

DOI: https://doi.org/10.5114/aoms/128275

Copyright @ 2022 Termedia \& Banach

\begin{abstract}
Introduction: This study aimed to analyze the correlation between serum insulin-like growth factor 1 (IGF-1) and body weight and provide some bases for the clinical assessment of the factors influencing children's height.

Material and methods: A total of 333 children with a height of less than the $10^{\text {th }}$ percentile were enrolled in this study. Among these children, 212 were male and 121 were female. The age range of these children was 5-14 years. Serum IGF-1 level was detected and the Z-scores (SDS) of the children's height, weight, and body mass index (BMI) were measured. The correlation among the factors was analyzed using Pearson's correlation analysis.

Results: Age, body weight, body weight SDS, BMI and BMI SDS were all correlated with serum IGF-1 level $(p<0.0001)$. There was also a strong correlation between body weight and serum IGF-1 level $(r=0.718)$ and a weak correlation between serum IGF-1 level and body weight SDS $(r=0.359)$. BMI SDS was weakly correlated with serum IGF-1 $(r=0.258)$. The correlation coefficients of age and BMI with serum IGF-1 were 0.622 and 0.536 , respectively.

Conclusions: The correlation between body weight and serum IGF-1 level is not high and it can provide some basis for the clinical assessment of the factors influencing children's height. However, it is not the main factor affecting height.
\end{abstract}

Key words: IGF-1, weight, BMI, low height children, correlation analysis.

\section{Introduction}

Serum insulin-like growth factor 1 (IGF-1) is a peptide containing more than 70 amino acids and can promote the growth of cartilage. IGF-1 is mainly produced by hepatocytes but part of it also comes from stromal cells and osteoblasts [1]. IGF-1 can promote cell proliferation and differentiation by promoting the synthesis of DNA, RNA, and protein and can also promote cell secretion [2]. IGF-1 is one of the important ???factors that insulin plays a role in with its target organs???. Through the IGF-1 pathway, insulin can promote glucose metabolism and transport, thereby promoting the synthesis of fat and glycogen [3]. So, IGF-1 is very important for the metabolism and growth of organisms.

Human height is affected by many factors, such as genetic factors, nutritional status, mental factors, and so on. The growth hormone $(\mathrm{GH})$ is also a very important factor for height. A previous study revealed that

\author{
Corresponding author: \\ Xianglan Wen \\ Zhuzhou Central Hospital \\ China \\ E-mail: xianglanwen99@163. \\ com
}


$\mathrm{GH}$ can directly promote the growth of bone and make the human body grow tall; however, it can promote IGF-1 synthesis by acting on the liver $\mathrm{GH}$ receptor and promote bone growth through IGF-1, while IGF-1 can react and inhibit the release of pituitary GH [4]. Therefore, IGF-1 is also considered to be one of the factors affecting height [5].

There are many factors affecting the level of IGF1 , such as age, gender, body mass index (BMI), region, nutritional status, and physical exercise [6-8]. Diabetes affects the level and activity of circulating insulin-like growth factor. Different types of diabetes affect the activity of insulin-like growth factor differently. The disorder of insulin-like growth factor in diabetic patients may be involved in the occurrence and development of diabetic nephropathy and diabetic retinopathy [8]. At present, there are many studies on the correlation between newborn birth weight and IGF-1 in cord blood. It was found that the level of IGF-1 in the study group with intrauterine growth retardation (IUGR)/fetal growth restriction (FGR) was lower than that in the normal group [9], indicating that fetal weight is related to IGF-1 level. How children's weight correlates with IGF-1 as they age is unclear. In clinical practice, most parents of short or undersized children require doctors to increase the children's weight to promote height growth, but its scientific nature needs to be verified. Thus, this study aimed to analyze the correlation between serum insulin-like growth factor 1 (IGF-1) and body weight and provide some bases for the clinical assessment of the factors influencing children's height.

\section{Material and methods}

\section{Study subjects}

From January 2017 to June 2018, 333 healthy children aged 5-14 years who were shorter than the $10^{\text {th }}$ percentile of the same age and first visited the Growth and Development Clinic of the Children's Health Care Department of our hospital were enrolled. Among these children, 212 were boys and 121 were girls. The children's body weight and serum IGF-1 were measured to investigate the correlation between serum IGF-1 and body weight and to provide some bases for the clinical assessment of the factors influencing children's height.

The current study has been approved by the Ethics Committee of our hospital, and all participants' parents signed written informed consent.

\section{Inclusion criteria}

Diagnostic criteria for low height: According to the "Growth Reference Standard for Children Aged 0-18 Years in China" formulated based on the survey data of children's physical development in nine provinces and cities in 2005, children with a height of less than the $10^{\text {th }}$ percentile were included.

At the children's first visit to the clinic, their serum IGF-1 was measured, as well as severe growth retardation (SGA), chronic organic diseases (liver, kidney, heart, lung, endocrine and metabolic diseases, and bone development disorders), psychological and serious emotional disorders and chromosomal abnormalities were excluded by history inquiry, physical examination, biochemical examination, and psychological evaluation screening. The children's physical development was measured by specially assigned persons and according to the formula (measured value-mean value of the same age group)/standard deviation, the Z-score (SDS) value of height, body weight, and the BMI of all children were calculated.

\section{Specimen collection and processing}

Three $\mathrm{ml}$ of fasting venous blood was withdrawn from each child in the morning. There was no anticoagulant in the collection tube. The blood was fully agglutinated, placed in a centrifuge, and was centrifuged at $2000 \mathrm{rpm}$ for more than 12 minutes. The upper serum was transferred and placed in a $2 \mathrm{ml}$ Eppendorf tube and the IGF-1 value of the sample was determined by the chemiluminescence method with an IMMULITE2000 instrument.

\section{Statistical analysis}

Data analysis was conducted using the software SAS9.4. Measurement data were expressed as mean \pm standard deviation $(x \pm S D)$. All measurement data were normally distributed as tested by the Shapiro-Wilk test. The correlation among the factors was analyzed using Pearson's correlation analysis. $\mathrm{P}<0.05$ was considered statistically significant.

\section{Results}

\section{General data}

The general data of all 333 children are shown in Table I. The average age of the boys and girls was $9.02 \pm 2.91$ and $8.68 \pm 2.71$ years, respectively. The average bodyweight of the boys and girls was $23.71 \pm 8.63 \mathrm{~kg}$ and $21.93 \pm 7.11 \mathrm{~kg}$, respectively. The average BMI of the boys and girls was 15.53 \pm 2.33 and $15.04 \pm 1.91$, respectively. The serum IGF-1 level of boys and girls was $172.71 \pm 120.74$ $\mathrm{ng} / \mathrm{ml}$ and $189.09 \pm 113.88 \mathrm{ng} / \mathrm{ml}$, respectively.

\section{The correlation between serum IGF-1 level and various indexes}

Age, body weight, body weight SDS, BMI, and BMI SDS were all correlated with serum IGF-1 lev- 
Table I. General data

\begin{tabular}{|lcccccc|}
\hline Gender & Age (years) & Weight $(\mathrm{kg})$ & Weight SDS & BMI & BMI SDS & IGF-1 (ng/ml) \\
\hline Boys $(n=212)$ & $9.02 \pm 2.91$ & $23.71 \pm 8.63$ & $-1.66 \pm 0.70$ & $15.53 \pm 2.33$ & $-0.49 \pm 0.83$ & $172.71 \pm 120.74$ \\
\hline Girls $(n=121)$ & $8.68 \pm 2.71$ & $21.93 \pm 7.11$ & $-1.66 \pm 0.79$ & $15.04 \pm 1.91$ & $-0.37 \pm 0.67$ & $189.09 \pm 113.88$ \\
\hline
\end{tabular}

el $(p<0.0001)$. According to the correlation coefficient, there was a strong correlation between bodyweight and serum IGF-1 level $(r=0.718)$ and a weak correlation between bodyweight and bodyweight SDS $(r=0.359)$. BMI SDS was weakly correlated with serum IGF-1 $(r=0.258)$. The correlation coefficients of age and $\mathrm{BMI}$ with serum IGF-1 levels were 0.622 and 0.536 , respectively (Table II).

Scatter diagram of the correlation between the bodyweight SDS and serum IGF-1 level and the BMI SDS and serum IGF-1 level

The correlation between the bodyweight SDS and serum IGF-1 level is shown in Figure 1, which reveals that the correlation analysis value $r$ was 0.359 , which indicates a weak positive correlation. The correlation between the BMI SDS and serum IGF-1 level is shown in Figure 2, which also reveals that the correlation analysis value $r$ was 0.258 , which indicates a weak positive correlation.

\section{Discussion}

IGF-1 is a kind of multifunctional cell proliferation regulator that consists of more than $70 \mathrm{ami}$ no acids. The liver is an important place for the human body to synthesize protein. $\mathrm{GH}$ in blood circulation binds to $\mathrm{GH}$ binding protein (GHBP) and binds to the $\mathrm{GH}$ receptor (GHR) on the cell membrane of the liver tissue through GHBP, and the latter causes IGF-1 to be produced in the liver. Also, $90 \%$ of IGF-1 is synthesized in the liver [10]. The synthesis and secretion of IGF-1 are controlled by the GH level and IGF itself has a negative feedback regulatory effect on $\mathrm{GH}$ secretion; therefore, the GH/IGS-1 axis has a crucial impact on height $[11,12]$.

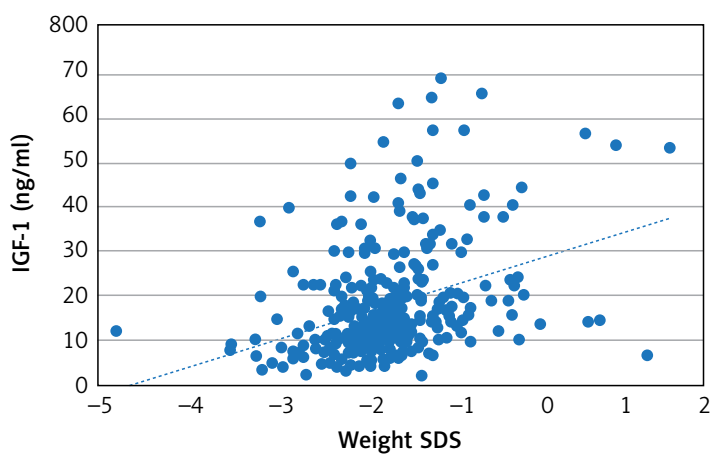

Figure 1. Scatter diagram of body weight SDS and serum insulin-like growth factor 1 (IGF-1) level, $r=0.359$, showing a weak positive correlation
Table II. Correlation between serum IGF-1 level and various indexes

\begin{tabular}{|lcc|}
\hline Parameter & \multicolumn{2}{c|}{ IGF-1 } \\
\cline { 2 - 3 } & $\begin{array}{c}\text { Correlation } \\
\text { coefficient }(r)\end{array}$ & $P$-value \\
\hline Age & 0.622 & $<0.0001$ \\
\hline Weight & 0.718 & $<0.0001$ \\
\hline Weight SDS & 0.359 & $<0.0001$ \\
\hline BMI & 0.536 & $<0.0001$ \\
\hline BMI SDS & 0.258 & $<0.0001$ \\
\hline
\end{tabular}

A previous study revealed that the physical growth of children was closely correlated to IGF-1 from the beginning of intrauterine growth and the birth weight was also relatively highly correlated with the IGF-1 level in cord blood. IGF-1 concentration presents a small peak at 2-3 months after birth, which decreases slowly in the period of infancy and young childhood, gradually increases in the period of childhood, and increases significantly in the period of adolescence [13]. It is also consistent with the law of children's height and body weight growth. Many previous studies suggested that the IGF-1 level was correlated with age, gender, puberty, heredity, environmental factors, nutritional status, and diseases [14, 15] and is a regulatory factor with complex influence factors. Some studies on the effect of malnutrition on IGF-1 revealed that malnutrition could change the GH-IGF-1 axis at multiple levels, for example, causing high expression of GH mRNA in the pituitary and low expression of GHR mRNA in the liver to reduce the expression of IGF-1 mRNA in the liver, accelerate the decomposition of IGF-1, affect the binding of IGF-1 to its protein, and weaken the biological activity of IGF-1 while causing acquired

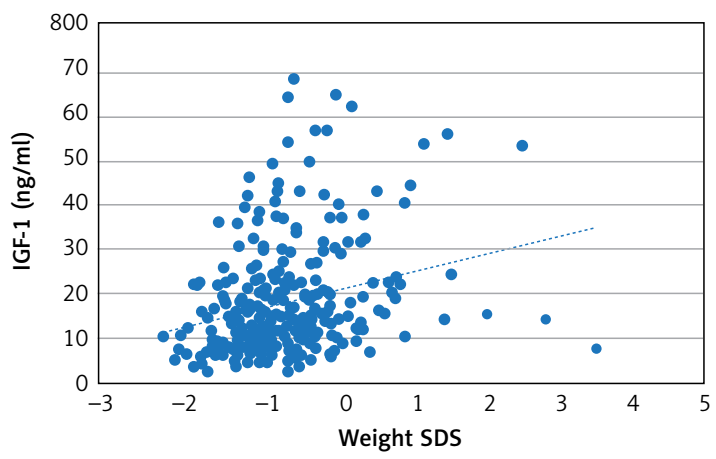

Figure 2. Scatter diagram of BMI SDS and serum insulin-like growth factor 1 (IGF-1) level, $r=0.258$, showing a weak positive correlation 
$\mathrm{GH}$ resistance and a significant decrease in serum IGF-1 level [16].

In clinical practice, short patients or children with low weight are common and their parents often emphasize that their child's growth is limited due to poor appetite. However, it is not known whether these children's height growth is affected by nutritional problems or if growth retardation is induced by impacts on both height and body weight. Through this study, it can be seen that there was a relatively strong correlation between body weight and IGF-1 in the special population that met the inclusion criteria. This also revealed that bodyweight is correlated with height to some extent and low bodyweight in childhood may affect height development. However, the bodyweight is affected by age and other factors; therefore, in the analysis of the bodyweight SDS value adjusted for all age groups, the correlation between it and IGF-1 is much lower. We therefore speculate that body weight is not a very important factor affecting IGF-1 but one of them and IGF-1 may be more closely correlated with other factors, such as genetic factors. This suggests that body weight has an effect on height, but only supplementing nutrition for short stature children under the requirements of parents may delay the treatment time of children, so that they cannot reach their ideal height. It also remains to be studied, for children with severe malnutrition, when the curative effect of GH treatment is not good, whether appropriate nutrition intervention can be given to reduce $\mathrm{GH}$ resistance and improve the IGF-1 level to improve treatment effects. This still needs further analysis.

Further studies are also needed to determine the factors affecting serum IGF-1. It remains to be determined which genetic or environmental factor has the dominant effect. The investigators hope to clarify this issue through more research, thereby providing new ideas and methods for the treatment of low height in children.

In conclusions, this study revealed that age, body weight, body weight SDS, BMI, and BMI SDS are all correlated with serum IGF-1 level. There is a strong correlation between body weight and serum IGF-1 level, a weak correlation between body weight and body weight SDS, and a weak correlation between BMI SDS and serum IGF-1. Therefore, the correlation between body weight and serum IGF-1 level is not high. This provides some bases for the clinical assessment of the factors influencing children's height, but serum IGF-1 is not the main factor affecting height.

\section{Conflict of interest}

The authors declare no conflict of interest.

\section{References}

1. Ge QW, Zhu ZY. The relationship between IGF-1, IGFBP3 and growth hormone deficiency dwarfism. J Clin Exp Med 2017; 16: 255-7.

2. Lai HT, Huang QS, Huang BQ, et al. Significance of detection of IGF-1 and IGFBP-3 in serum of children with dwarfism. China Continuing Medical Education 2016; 8: 25-6.

3. Aguirre GA, De Ita JR, de la Garza RG, Castilla-Cortazar I. Insulin-like growth factor-1 deficiency and metabolic syndrome. J Transl Med 2016; 14: 3.

4. Song HS, Choi WB, Song JS, Hwang IT, Yang S. Relationship between serum insulin-like growth factor-1, IGF binding protein-3 levels and body height before and after gonadotropin-releasing hormone agonist therapy. Ann Pediatr Endocrinol Metab 2014; 19: 208-13.

5. Song W, Qiao Y, Xue J, Zhao F, Yang X, Li G. The association of insulin-like growth factor-1 standard deviation score and height in Chinese children with type 1 diabetes mellitus. Growth Factors 2018; 36: 274-82.

6. ???Xu Y. Reference range and influencing factors of serum IGF-1 in Chinese normal adults. Beijing: Clinical College of Peking Union Medical College; 2016, 9-48.???

7. Schneider HJ, Saller B, Klotsche J, et al. Opposite associations of age-dependent insulin-like growth factor-I standard deviation scores with nutritional state in normal weight and obese subjects. Eur J Endocrinol 2006; 154: 699-706.

8. Kelly PJ, Eisman JA, Stuart MC, Pocock NA, Sambrook PN, Gwinn TH. Somatomedin-C, physical fitness, and bone density. J Clin Endocrinol Metab 1990; 70: 718-23.

9. Cai JY, Zhang HX, Zhang JT, et al. Meta-analysis of the relationship between IGF-1 in cord blood and abnormal birth weight of newborn. The Seventh National Academic Conference on epidemiology. Nanjing: Chinese Preventive Medicine Association; 2014, 99.

10. Yu P, Zhu HJ, Pan H. Research progress of growth hormone insulin-like growth factor-1 axis related single gene deficiency dwarfism. Chinese Journal of Health Laboratory Technology 2015; 25: 2054-6.

11. Hellström A, Ley D, Hansen-Pupp I, et al. Insulin-like growth factor 1 has multisystem effects on foetal and preterm infant development. Acta Paediatr 2016; 105: 576-86.

12. Boyne MS, Thame M, Bennett F, et al. The relationship among circulating insulin-like growth factor (IGF-1), IGF-binding proteins-1 and -2, and birth anthropometry: a prospective study. J Clin Endocrinol Metab 2003; 88: 1687-91.

13. Lofqvist C, Andersson E, Gelander L, et al. Reference values for insulin-like growth factor-binding protein-3 (IGFBP-3) and the ratio IGF-1/IGFBP-3 throughout childhood and adolescence. J Clin Endocrinol Metab 2005; 90: 1420-7.

14. Gautam D, Jeon J, Starost MF, et al. Neuronal M3 muscarinic acetylcholine receptors are essential for somatotroph proliferation and normal somatic growth. Proceed Natl Acad Sci U S A 2009; 106: 6398-403.

15. Mohamadi A, Martari M, Holladay CD, et al. Mutation analysis of the muscarinic cholinergic receptor genes in isolated growth hormone deficiency type IB. J Clin Endocrinol Metab 2009; 94: 2565-70.

16. ???Gao XJ. Regulation of growth hormone insulin and leucine in rats with severe malnutrition. Guangdong: Southern Medical University; 2015, 40-59.??? 